\title{
Bibliometric Analysis of Research on Learning Analytics Based on Web of Science Database
}

\author{
Tarık TALAN ${ }^{1}$, Muhammet DEMİRBILEK ${ }^{2}$ \\ ${ }^{1}$ Gaziantep Islam Science and Technology University, Gaziantep, Turkey \\ ${ }^{2}$ Department of Educational Sciences, Faculty of Education, Suleyman Demirel Universty, \\ Isparta, Turkey \\ e-mail:ttalan46@hotmail.com,mdbilek@gmail.com
}

Received: October 2021

\begin{abstract}
The purpose of this study is to reveal the status of scientific publications on learning analytics from the past to the present in terms of bibliometric indicators. A total of 659 publications on the subject between the years 2011-2021 were found in the search using keywords after various screening processes. Publications were revealed through descriptive and bibliometric analyses. In the study, the distribution of publications by years and citation numbers, the most published journals on the subject, the most frequently cited publications, the most prolific countries, institutions and authors were examined. In addition, the cooperation between the countries, authors and institutions that publish on the subject was mentioned and a network structure was created for the relations between the keywords. It has been determined that research in this field has progressed and the number of publications and citations has increased over the years. As a result of the bibliometric analysis, it was concluded that the most influential countries in the field of learning analytics are the USA, Australia and Spain. The University of Edinburgh and Open University UK ranked first in terms of the number of citations and Monash University as the most prolific institutions in terms of the number of publications. According to the keyword co-occurrence analysis, educational data mining, MOOCS, learning analytics, blended learning, social network analysis keywords stand out in the field of learning analytics.
\end{abstract}

Keywords: bibliometric analysis, learning analytics, VOSviewer, Web of science.

\section{Introduction}

The use of information and communication technologies in education has not only expanded the scientific research opportunities and field of study, but also started to offer new opportunities in education. With the use of these technologies in education, new concepts in educational technologies began to be mentioned. One of these new concepts is "learning analytics", which has found an increasing use and interest in recent years. This concept originally emerged from collaborations between computer science and learning science researchers (Dawson et al., 2014). However, although the concept 
of learning analytics is a relatively new field, it has been met with interest not only by software developers but also by researchers doing research on technology integration in education (Viberg et al., 2018). In addition, it has been determined in the literature that although studies on learning analytics are carried out at different education levels from pre-school to graduate education, higher education level is preferred more intensely.

Learning analytics refers to the application of data analytics methods to learning processes and its contexts. The learning analytics concept has strong ties with many fields such as web analytics, machine learning, business intelligence, educational data mining, social network analysis, academic analytics (Elias, 2011). Therefore, the learning analytics concept is used to obtain necessary and useful information, reflect one's previous learning, and improve teaching and learning (Dyckhoff et al., 2012).

Increasing demand for e-learning services and the use of big data in online environments for both educational and administrative purposes has enabled the development of learning analytics to process learner data. (Booth, 2012; Del Blanco et al., 2013; Johnson et al., 2012; Siemens, 2013; Sin and Muthu, 2015). Therefore, this concept has come to the fore as one of the newest working areas of e-learning in recent years. However, although it is new, it has an important potential in the learning and teaching process (Ferguson, 2012). Unlike traditional methods, the techniques used in learning analytics enable faster processing of learning data (Siemens and Long, 2011). The basic assumption of the learning analytics field is that the data on learner behavior and the knowledge that will emerge provide an advantage to the trainer, the individual and the education administrators (Dyckhoff et al., 2012; Slade and Prinsloo, 2013).

Learning analytics can basically be defined as the collection, measurement, analysis and reporting of data about learners to understand and optimize learning and the environments in which learning takes place (Siemens 2010; Siemens and Gasevic, 2012; Siemens and Long 2011). Learning It is a tool to analyze quantitative data collected from Massive Open Online Courses (MOOCS), Learning Management Systems (LMS), virtual learning environments, and other online learning systems (Fidalgo-Blanco et al., 2015). Horizon Report, which makes predictions based on technological developments, defines learning analytics as the collection and interpretation of large amounts of data generated by learners to evaluate and assess academic achievement, predict future learning performance, and identify current problems in learning (Johnson et al., 2011). Therefore, learning analytics provides vital information to improve the learning performance and achievement of learners and increase the efficiency of learning (Dyckhoff et al., 2012). Learning analytics emphasizes measuring and understanding the performance of students individually and how this affects the overall functioning of the institution (Daniel 2017; Romero and Ventura 2010). In addition, learning analytics can provide better feedback on the learning process (Kloos et al., 2013). Thanks to the feedback received from learning analytics data, the design of learning environments can be rearranged and improved.

Learning analytics; pedagogy has a multidisciplinary structure consisting of fields such as business intelligence, data mining, artificial intelligence, machine learning, and statistics (Papamitsiou and Economides, 2014; Siemens, 2013). For example, statistical methods are often used to predict early detection of potential problems. The basic assumption of the learning analytics field is that the data on learner behavior and the knowledge that will emerge provide an advantage to the trainer, the individual and the 
education administrators (Dyckhoff et al., 2012; Slade and Prinsloo, 2013). In this context, early intervention is a good example for the use of learning analytics, especially by designing more effective and sustainable education programs, monitoring students' course follow-up status, discovering hidden information, and detecting students with a tendency to drop out (Johnson et al., 2013; Macfadyen and Dawson, 2010). When learning analytics is interpreted and applied correctly, it provides important contributions not only to students but also to other stakeholders such as educators, administrators and policy makers who take part in the education process (Ifenthaler and Widanapathirana, 2014). For example, learning analytics can provide student-specific personalized feedback and provide advice and guidance to improve the student's learning process and results (Greller and Drachsler, 2012; Tempelaar et al., 2015). Again, learning analytics provide important information in terms of evaluating whether the goals are achieved, making predictions about the future in order to increase the success of students, comparing the performance of the students, analyzing and evaluating the effectiveness of the curriculum (Gašević et al., 2016; Marks et al., 2016; Siemens et al., 2013; Zilvinskis and Willis, 2019). In this way, educators can make suggestions to students to increase success and decrease failure rates (Osmanbegovic and Suljic, 2012; Siemens and Long, 2011). In addition, learning analytics can make important contributions to the early detection of students at risk, providing comprehensive data on students' interest and participation in the course, personalisation of learning environments, and the development and improvement of courses and curricula (Booth, 2012; Siemens, 2010; Siemens et al., 2013; West, 2012). In this way, it can be said that actions for student success can be implemented faster and problems can be determined in advance. Therefore, such contributions make teaching more effective and make evaluation easier (Rienties et al., 2017). It can be said that learning analytics, which has been studied extensively recently, has some problems and weaknesses that need to be resolved (Bozkurt, 2016). In particular, the possibility of misclassification of the observed pattern, misinterpretation of results due to factors arising from human judgments, and conflicting findings during application are some of the weaknesses of learning analytics (Papamitsiou and Economides, 2014). One of these problems is the ethical and legal situations that may arise before, during and after learning analytics processes (Greller and Drachsler, 2012; Khalil and Ebner, 2015; Slade and Prinsloo, 2013). This situation negatively affects the development of learning analytics from different perspectives. However, the uniqueness of learning analytics is once again understood when the opportunities it offers to the stakeholders involved in the learning-teaching processes to provide more effective learning experiences. Although the concept of learning analytics has recently entered the literature, it has been emphasized by many researchers that it has an important potential in the education process in a short time (Koca, 2019).

When the relevant literature is examined, learning analytics have been studied providing comprehensive data on students' learning outcomes and class participation ( $\mathrm{Lu}$ et al., 2017). Furthermore, it has been used to predict the academic performance of students (Ibrahim and Rusli, 2007), their mistakes (Wang and Mitrovic, 2002), and students' satisfaction with their instructors (Agaoglu, 2016). In addition, learning analytics have been subject to research providing early intervention against possible problems 
that may arise (Wise, 2014), and to identify students at risk (e.g., poorly performing) to intervene early (Casey and Azcona, 2017).

The common purpose of learning analytics in estimation and recommendation research are preventing students from dropping out of a course by predicting their possible success in a course, enabling instructors to organize their teaching strategies, and increasing the quality of educational institutions (Badra et al., 2016).

Furthermore, learning analytics based on analyzing student data helps academic planners to make decisions about students' achievement, restructure curriculum to increase students' performance, and reduce the dropout rate of students (Koca, 2019; Verma and Thakur, 2017).

\subsection{Purpose of the Research}

It has been observed that the number of scientific researches on learning analytics has dramatically increased, especially in recent years. Evaluating, interpreting and summarizing the publications produced in the field of learning analytics, whose importance and popularity is increasing day by day, provides the opportunity to see the effectiveness and progress of scientific publications on this subject. It can be said that the bibliometric method, which includes analyzes such as research efficiency, citation rankings, cooperation between authors, institutions or countries, concept or citation associations, has the potential to make significant contributions to the literature. In this respect, in order to contribute to the development of the relevant literature in our research, it has been tried to reveal the situation in terms of learning analytics and scientific publications from the past to the present, and bibliometric indicators. As a result of the findings, general trends and research focuses of learning analytics can be revealed and the connection between a publication on the subject and other publications can be analyzed numerically. In addition, it is thought that approaching the researches in this field with a general point of view will be guiding for future research, will guide field experts to determine different study topics, and will benefit researchers and practitioners. In this way, repetition of researchers can be prevented and it can contribute to the making of original publications on the subject. In this direction, answers to the following questions will be sought:

1. What is the distribution of articles published on learning analytics by publication years?

2. Which countries are active within the scope of published articles on learning analytics?

3. Which institutions are active within the scope of published articles on learning analytics?

4. What are the authors and the number of publications that contribute the most to the field within the scope of learning analytics?

5. Which journals are active within the scope of published articles on learning analytics?

6. What is the structure of co-author analysis (author, country/region, institution)?

7. What kind of structure emerges in terms of co-citation analysis (author)?

8. What kind of structure emerges in terms of keyword co-occurrence analysis? 


\section{Method}

In this study, publications on learning analytics in the Web of Science Core Collection (WoS) database were examined using the bibliometric analysis method. Bibliometrics, which is frequently used in many different disciplines; it is a method in which mathematical and statistical methods are used to measure and analyze scientific publications (published books, journals, articles, etc.) obtained from various databases (Pritchard, 1969). In this method, publications related to a certain field or subject are classified according to countries, institutions, research groups or authors, and a wide variety of analysis techniques are used, including citation-based and performance-based analyzes (Gaviria-Marin et al., 2019). Thus, the information classified under a single study can be accessed as a whole. In this context, bibliometric studies allow the evaluation of certain features of scientific studies in terms of both quantity and quality (Al and Soydal, 2012). In the bibliometric method, which has an important place in scientific studies in recent years, various key terms such as co-authorship network, citation network and cooccurrences network are of great importance.

\subsection{Data Collection}

WoS, one of the world's largest scientific publication databases, was used to obtain the data of this study. The reason why the study was carried out in WoS is that the related database, such as Science Citation Index Expanded (SCI-E), Arts \& Humanities Citation Index (A\&HCI), Science Citation Index (SCI), Social Sciences Citation Index (SSCI), which are seen as respected citation indexes by academic circles. It covers directories and allows research on a wide range of literature. In addition, WoS is accepted as one of the world's leading academic databases with the abundance and diversity of the publications it scans. It has been tried to reach related researches by using advanced search query and filtering options of WoS. In Table 1, the codes written in the database are presented.

In the WoS database, the publications with the phrase "Learning Analytics" in the title, abstract and keywords are scanned and listed. The last scan was carried out in June 2021. There is no filtering in the language of the broadcasts. Although all the years in the database were selected as the time period, the publications between 2011 and 2021 were

Table 1

Search Query in Web of Science

\begin{tabular}{ll}
\hline Topic & Learning Analytics \\
\hline Categories & $\begin{array}{l}\text { Education Scientific Disciplines OR Education Educational Research OR } \\
\text { Education Special OR Psychology Educational }\end{array}$ \\
Document types & Article, Early Access, Review Articles \\
Timespan & All years \\
Indexes & SSCI, SCI-EXPANDED, A\&HCI \\
\hline
\end{tabular}


included in the research, since the research on the subject has been in the database since 2011. The basic categories of WoS such as "Education Scientific Disciplines", "Education Educational Research", "Education Special", "Psychology Educational" were evaluated. In addition, with the help of the filtering features of WoS, only the articles indexed in SSCI, SCI-EXPANDED, A\&HCI were included in the analysis, and publications such as conference booklets, book chapters, editorial articles were identified and removed from the data set. As a result of the filters, a total of 659 articles were identified and included in the analysis. In these articles, bibliographic data were obtained.

\subsection{Data Analysis}

The data obtained from the research were analyzed with the descriptive analysis technique. Within the content analysis, the own system of the WoS database was used. In addition, relationships and density maps for various variables were created using the visual mapping program VOSviewer (Version 1.6.16, Center for Science and Technology Studies of Leiden University). Before the maps were created, terms with the same meaning were combined. The data obtained were examined in terms of countries, journals, publication years, number of publications and subject trends and institutions supporting the research. In addition, co-author (author, country/region, institution), cocitation (author) and keyword co-occurrence analysis of the publications were also conducted during the analysis process.

\section{Findings}

Within the framework of the purpose of the research, the following findings were obtained. Findings related to the research are shown in tables and figures.

\subsection{Distribution of Publications by Years}

In the study, primarily the distribution of publications on learning analytics in the WoS database by years and citation numbers was examined. The results are shown in Fig. 1.

Analyzing Fig. 1, it is seen that basic research on learning analytics started in 2011. For this reason, publications made between 2011-2021 were included in the scope of bibliometric analysis. It has been observed that there has been an increase in the publications from the past to the present and it has started to be expressed more clearly by different researchers. In addition, the studies published in the last three years constitute approximately $59 \%$ of the total publications. It is also seen that the number of citations has increased over the years. The highest number of citations and publication year was 2020. However, there is a decrease in the number of publications in 2021. As we conducted the research in June 2021, not all publications from this year have yet been indexed in WoS. 


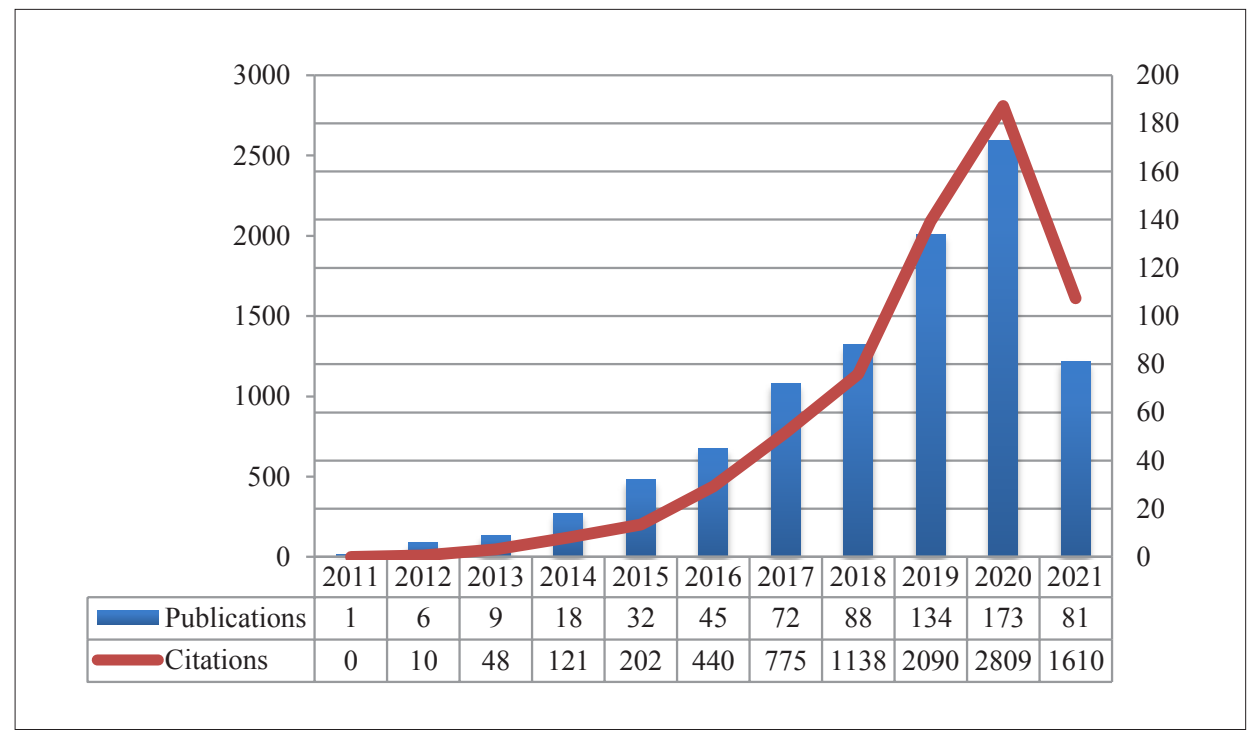

Fig. 1. Times cited and publications over time.

\subsection{Distribution of Most Prolific Countries/Regions}

The 10 most prolific countries/regions were examined in the study. Publications by countries/regions factor, it was evaluated with 5 indicators, namely the total number of citations (TC), the total number of publications (TP), the average number of citations per publication (TC/TP), the percent of TP accounting for total publications (\%TP) and $\mathrm{H}$-index. These indicators, which are widely used in bibliometric analysis, reflect the general status of publications by country. The Table 2 shows data distribution of countries/regions.

Table 2

The 10 most prolific countries/regions

\begin{tabular}{llrrrrr}
\hline Rank & Country/Region & \multicolumn{1}{c}{ TC } & TP & TC/TP & \% TP & H-index \\
\hline 1 & USA & 2485 & 172 & 14.45 & 25.98 & 27 \\
2 & Australia & 1517 & 93 & 16.31 & 14.05 & 20 \\
3 & Spain & 912 & 90 & 10.13 & 13.60 & 18 \\
4 & England & 1196 & 66 & 18.12 & 9.97 & 18 \\
5 & China & 339 & 58 & 5.84 & 8.76 & 9 \\
6 & Netherlands & 845 & 44 & 19.20 & 6.65 & 13 \\
7 & Taiwan & 357 & 42 & 8.50 & 6.34 & 11 \\
8 & Canada & 810 & 37 & 21.89 & 5.59 & 14 \\
9 & Germany & 433 & 31 & 13.97 & 4.68 & 10 \\
10 & Scotland & 913 & 29 & 31.48 & 4.38 & 15 \\
\hline
\end{tabular}


According to Table 2, the USA is the most prolific country with 172 publications, followed by Australia (93), Spain (90) and England (66), respectively. The country with the highest average number of citations per publication (TC/TP) is Scotland. It is followed by Canada (21.89), the Netherlands (19.2) and the England (18.12). On the other hand, the countries with the highest H-index are the USA (27), Australia (20), Spain (18) and England (18). The fact that many of the most prolific countries/regions in terms of number of publications are also the most cited countries shows the quality of their work in this field.

\subsection{Distribution of Most Prolific Institutions}

In the study, the total publication and citation rankings of the institutions that publish on the subject were examined. Table 3 presents data on the 10 most prolific institutions in this field.

According to the Table 3 the University of Edinburgh (Scotland) and Open University UK (England) stand out as the top institutions in terms of the total number of citations. Monash University (Australia) is the most prolific institution in terms of total number of publications. This indicator shows that institutions conduct in-depth research on the subject. In addition, it can be stated that institutions in Australia have a great interest in the subject. Indeed, four of the 10 most prolific institutions are located in Australia.

\subsection{Distribution of Most Cited Publications}

Within the scope of the research, information about the most cited publications on the subject was also examined. The data related to this are shown in Table 4. Average num-

Table 3

The top 10 most prolific institutions

\begin{tabular}{rlllrrrr}
\hline Rank & Institution & $\begin{array}{l}\text { Country/ } \\
\text { Region }\end{array}$ & TP & TC & TC/TP & \%TP & $\begin{array}{l}\text { Link } \\
\text { strength }\end{array}$ \\
\hline 1 & Monash University & Australia & 27 & 176 & 6.52 & 17.20 & 384 \\
2 & University of Edinburgh & Scotland & 21 & 665 & 31.67 & 13.38 & 454 \\
3 & Open University UK & England & 20 & 665 & 33.25 & 12.74 & 399 \\
4 & Universidad Carlos III De Madrid & Spain & 17 & 219 & 12.88 & 10.83 & 105 \\
5 & University of Sydney & Australia & 14 & 455 & 32.50 & 8.92 & 380 \\
6 & University of South Australia & Australia & 14 & 252 & 18.00 & 8.92 & 260 \\
7 & National Central University & Taiwan & 12 & 165 & 13.75 & 7.64 & 100 \\
8 & University of Florida & USA & 12 & 86 & 7.17 & 7.64 & 73 \\
9 & Open University Netherlands & Netherlands & 10 & 434 & 43,40 & 6,37 & 248 \\
10 & University of Technology Sydney & Australia & 10 & 105 & 10.50 & 6.37 & 136 \\
\hline
\end{tabular}


ber of citations of publications on the subject (average per item) is 14.13. The average number of citations of the top 10 most cited publications is 184.1 .

The Table 4 provides information on the most frequently cited publications on the subject in WoS. According to these data, the most frequently cited publication is Greller \& Drachsler (2012) with 294 citations. The author is followed by the publications of Shum \& Ferguson (2012), Kizilcec et al. (2017) and Papamitsiou \& Economides (2014), respectively. Five of the most cited publications were published in the Journal of Educational Technology \& Society. In addition, Kizilcec et al. (2017)'s article is the best publication by citation/year, indicating that the article has been widely recognized since its publication.

Table 4

The information of most cited publications

\begin{tabular}{|c|c|c|c|c|c|c|}
\hline Rank & Title & Authors & Year & Citation & $\begin{array}{l}\text { Citation/ } \\
\text { Year }\end{array}$ & Source \\
\hline 1 & $\begin{array}{l}\text { Translating Learning into Numbers: } \\
\text { A Generic Framework for Learning } \\
\text { Analytics }\end{array}$ & $\begin{array}{l}\text { Greller \& } \\
\text { Drachsler }\end{array}$ & 2012 & 294 & 29.4 & $\begin{array}{l}\text { Educational Techno- } \\
\text { logy \& Society }\end{array}$ \\
\hline 2 & Social Learning Analytics & $\begin{array}{l}\text { Shum \& } \\
\text { Ferguson }\end{array}$ & 2012 & 224 & 22.4 & $\begin{array}{l}\text { Educational Techno- } \\
\text { logy \& Society }\end{array}$ \\
\hline 3 & $\begin{array}{l}\text { Self-regulated learning strategies } \\
\text { predict learner behavior and goal } \\
\text { attainment in Massive Open Online } \\
\text { Courses }\end{array}$ & $\begin{array}{l}\text { Kizilcec } \\
\text { et al. }\end{array}$ & 2017 & 223 & 44.6 & $\begin{array}{l}\text { Computers \& } \\
\text { Education }\end{array}$ \\
\hline 4 & $\begin{array}{l}\text { Learning Analytics and Educatio- } \\
\text { nal Data Mining in Practice: } \\
\text { A Systematic Literature Review of } \\
\text { Empirical Evidence }\end{array}$ & $\begin{array}{l}\text { Papamitsiou } \\
\& \\
\text { Economides }\end{array}$ & 2014 & 220 & 27.5 & $\begin{array}{l}\text { Educational Techno- } \\
\text { logy \& Society }\end{array}$ \\
\hline 5 & $\begin{array}{l}\text { Learning analytics should not pro- } \\
\text { mote one size fits all: The effects } \\
\text { of instructional conditions in pre- } \\
\text { dicting academic success }\end{array}$ & $\begin{array}{l}\text { Gasevic } \\
\text { et al. }\end{array}$ & 2016 & 206 & 34.33 & $\begin{array}{l}\text { Internet And Higher } \\
\text { Education }\end{array}$ \\
\hline 6 & $\begin{array}{l}\text { Where is Research on Massive } \\
\text { Open Online Courses Headed? } \\
\text { A Data Analysis of the MOOC Re- } \\
\text { search Initiative }\end{array}$ & $\begin{array}{l}\text { Gasevic } \\
\text { et al. }\end{array}$ & 2014 & 152 & 19 & $\begin{array}{l}\text { International } \\
\text { Review of Research } \\
\text { In Open And } \\
\text { Distributed Learning }\end{array}$ \\
\hline 7 & $\begin{array}{l}\text { Design and Implementation of } \\
\text { a Learning Analytics Toolkit for } \\
\text { Teachers }\end{array}$ & $\begin{array}{l}\text { Dyckhoff } \\
\text { et al. }\end{array}$ & 2012 & 146 & 14.6 & $\begin{array}{l}\text { Educational Techno- } \\
\text { logy \& Society }\end{array}$ \\
\hline 8 & $\begin{array}{l}\text { Numbers Are Not Enough. Why } \\
\text { e-Learning Analytics Failed to In- } \\
\text { form an Institutional Strategic Plan }\end{array}$ & $\begin{array}{l}\text { Macfadyen } \\
\text { et al. }\end{array}$ & 2012 & 127 & 12.7 & $\begin{array}{l}\text { Educational Techno- } \\
\text { logy \& Society }\end{array}$ \\
\hline 9 & $\begin{array}{l}\text { Ethical and privacy principles for } \\
\text { learning analytics }\end{array}$ & $\begin{array}{l}\text { Pardo \& } \\
\text { Siemens }\end{array}$ & 2014 & 125 & 15.63 & $\begin{array}{l}\text { British Journal of } \\
\text { Educational Tech- } \\
\text { nology }\end{array}$ \\
\hline 10 & $\begin{array}{l}\text { The role of students' motivation } \\
\text { and participation in predicting } \\
\text { performance in a MOOC }\end{array}$ & $\begin{array}{l}\text { de Barba } \\
\text { et al. }\end{array}$ & 2016 & 124 & 20.67 & $\begin{array}{l}\text { Journal of Computer } \\
\text { Assisted Learning }\end{array}$ \\
\hline
\end{tabular}


Table 5

The top 10 most prolific authors

\begin{tabular}{lllrrrrrr}
\hline Rank & Authors & $\begin{array}{l}\text { Country/ } \\
\text { Region }\end{array}$ & TP & TC & TC/TP & \%TP & H-index & $\begin{array}{l}\text { Link } \\
\text { strength }\end{array}$ \\
\hline 1 & Gasevic, Dragan & Australia & 28 & 918 & 32.79 & 22.05 & 32 & 1060 \\
2 & Pardo, Abelardo & Australia & 18 & 587 & 32.61 & 14.17 & 20 & 790 \\
3 & Dawson, Shane & Australia & 12 & 607 & 50.58 & 9.45 & 14 & 547 \\
4 & Rienties, Bart & England & 12 & 150 & 12.50 & 9.45 & 22 & 353 \\
5 & Munoz-merino, Pedro J. & Spain & 11 & 114 & 10.36 & 8.66 & 19 & 122 \\
6 & Xing, Wanli & USA & 11 & 103 & 9.36 & 8.66 & 10 & 65 \\
7 & Delgado Kloos, Carlos & Spain & 10 & 162 & 16.20 & 7.87 & 9 & 133 \\
8 & Ogata, Hiroaki & Japan & 9 & 76 & 8.44 & 7.09 & 13 & 110 \\
9 & Drachsler, Hendrik & Germany & 8 & 474 & 59.25 & 6.30 & 20 & 413 \\
10 & Martinez-Maldonado, Roberto & Australia & 8 & 64 & 8.00 & 6.30 & 11 & 215 \\
\hline
\end{tabular}

\subsection{Distribution of Most Prolific Authors}

The authors who contributed to this field were also examined in the study. Authors are listed in terms of total number of publications and citations. According to the analysis report, 1716 authors have publications on the subject. The 10 most prolific authors by number of publications are listed in Table 5 .

When the table is examined, the top 3 most prolific authors on the subject are from Australia. Also, 2 authors are from Spain. Gasevic, Pardo and Dawson authors seem to come to the fore in terms of productivity and impact. The 10 most prolific authors contributed approximately $20 \%$ of the total published ( 659 publications) on the subject. The research areas of the authors are generally educational technology, technology assisted learning, collaborative learning.

\subsection{Journal Distribution of Publications}

Within the scope of the study, the citation analysis of the journals that published the most on the subject was examined. The data related to this are presented in Table 6 .

When the journal-based distribution of the publications is examined, the most published journals are "British Journal of Educational Technology" (55) and "Interactive Learning Environments" (52). When the number of citations per article is analyzed, it is seen that the journals "Educational Technology Society", "Computers \& Education", "British Journal of Educational Technology" and "Internet and Higher Education" come to the fore.

\subsection{Author Collaboration Network}

Author collaboration network has been established to detail the relationships of authors publishing on the subject. The obtained data are shown in Fig. 2 below. 
Table 6

Journal Distribution of Publications

\begin{tabular}{clrrrrr}
\hline Rank & Journal & TP & TC & TC/TP & \%TP & $\begin{array}{l}\text { Link } \\
\text { strength }\end{array}$ \\
\hline 1 & & & & & & \\
2 & British Journal of Educational Technology & 55 & 993 & 18.05 & 14.40 & 275 \\
3 & Interactive Learning Environments & 52 & 296 & 5.69 & 13.61 & 131 \\
4 & Computers \& Education & 47 & 1161 & 24.70 & 12.30 & 253 \\
5 & EEEE Transactions on Learning Technologies & 45 & 663 & 14.73 & 11.78 & 245 \\
6 & Educational Technology Society & 44 & 1388 & 31.55 & 11.52 & 283 \\
7 & Journal of Computer Assisted Learning & 37 & 234 & 6.32 & 9.69 & 166 \\
8 & International Review of Research in Open and Distri-- & 26 & 415 & 15.96 & 6.81 & 67 \\
& buted Learning & & & & & \\
9 & Internet and Higher Education & 24 & 894 & 37.25 & 6.28 & 187 \\
10 & Australasian Journal of Educational Technology & 22 & 139 & 6.32 & 5.76 & 98 \\
\hline
\end{tabular}

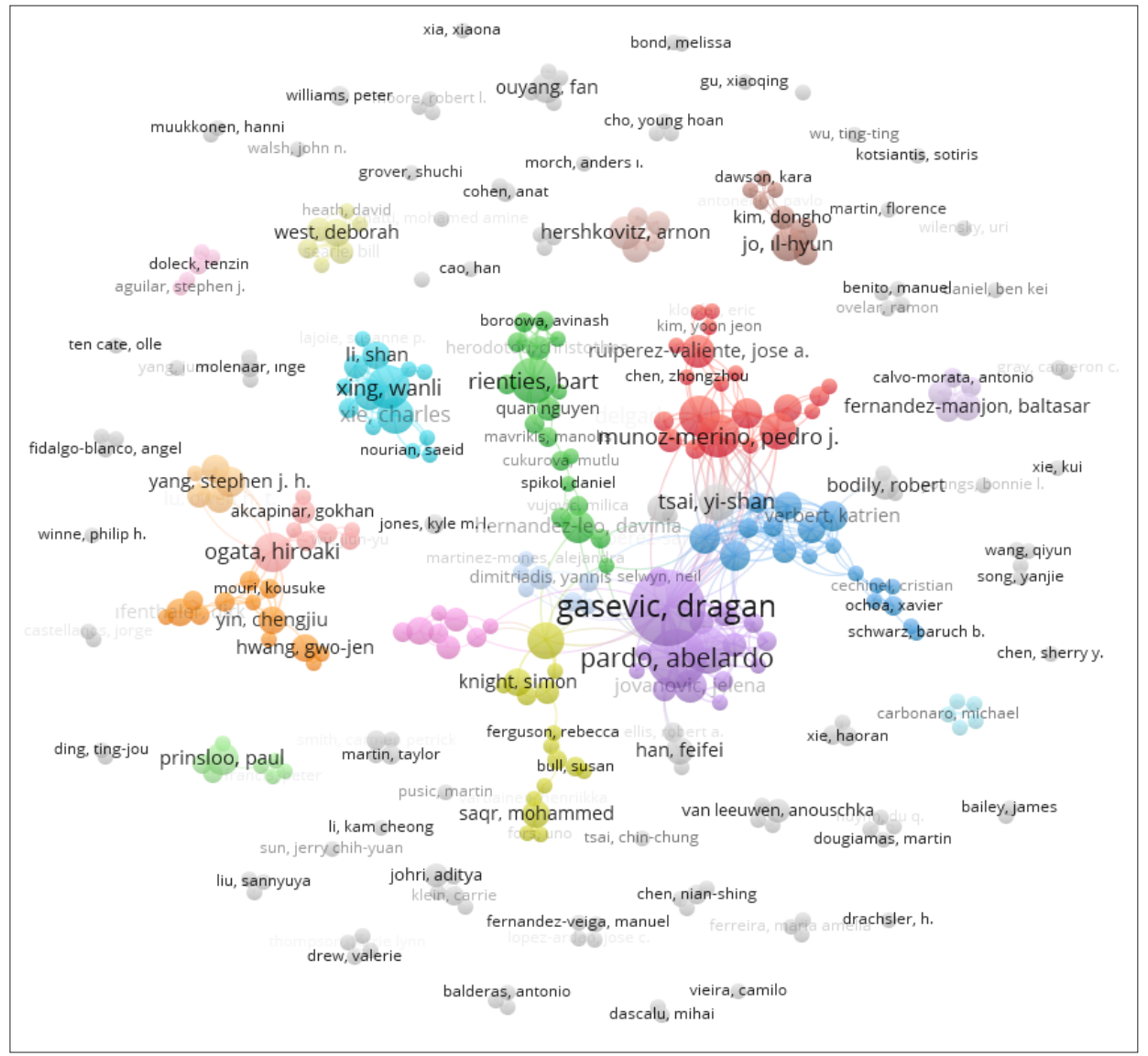

Fig. 2. The author collaboration network. 
After the analysis, 1716 authors who published on the subject were divided into 17 clusters. When the co-author analysis of the studies is examined, it is seen that the authors who publish together generally have separate publications and in small groups. Examples of notable author collaborations are Gasevic, D. (Australia), Pardo, A. (Australia), Dawson, S. (Australia), and Jovanovic, J. (Serbia). Collaboration was also found between Munoz-merino, P. J. (Spain), Delgado Kloos, C. (Spain), Ruiperez-Valiente, J. A. (Spain), and Drachsler, H. (Germany). As a result, Gasevic, Pardo and Dawson are the most cited authors on the subject and it can be said that they have many publications, researched the subject in depth and contributed to the field. However, some small clusters are also observed that are not associated with others. This implies the existence of smaller research communities and the lack of cooperation among such clusters.

\subsection{Country/Region Collaboration Network}

VOSviewer, a visual mapping program, was used to clearly examine the cooperation relations between the countries/regions that broadcast on the subject from 2011 to 2021. Co-author analysis for cross-country/regional cooperation is presented in Fig. 3.

In Fig. 3, different colors represent different clusters. As seen in the Fig. 3, two different clusters are formed. There are main clusters and relatively smaller clusters. If two countries or regions are closer to each other, it can be said that there is a strong connection between them. In addition, the thicker the links are, the greater the cooperation between these countries or regions. Accordingly, the most cooperated countries or regions are the US (31 connections), Spain (26 connections), England (23 connections), Netherlands (22 connections), Australia (21 connections), Germany (18 connections),

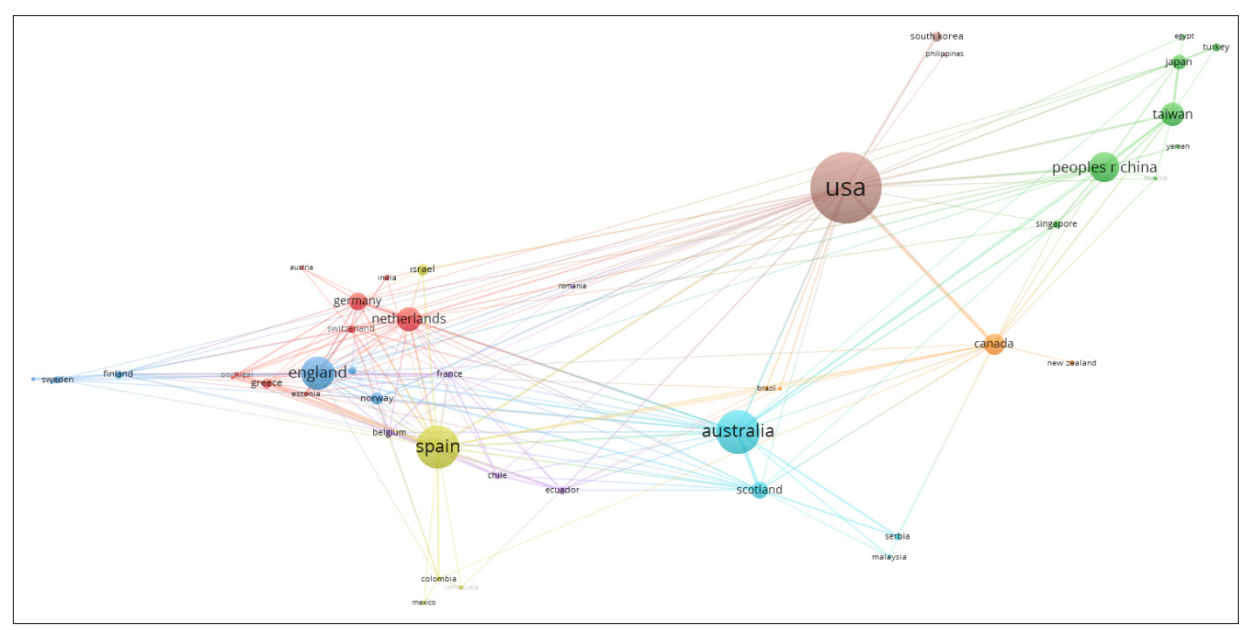

Fig. 3. The country/region collaboration network. 
France (17 connections) and Switzerland (17 connections). As a result, the United States is the most collaborative country among the other countries. The US often cooperates with China and Canada. On the other hand, although China and Taiwan have a large number of publications, but their connection strength is relatively low. This indicates that these two publications are generally carried out independently.

\subsection{Institution Collaboration Network}

VOSviewer was used to detail the analysis for co-authors' interagency collaboration. Fig. 4 shows the cooperative relationship of institutions from 2011 to 2021.

A total of 635 institutions have published on the subject and many institutions are intertwined with each other. In addition, it has been determined that there is no cooperation between some institutions. As can be seen in Fig. 4, when the institutions of the co-authors are examined, the dominant institutions such as Monash University (Australia), University of Sydney (Australia), Universidad Carlos III De Madrid (Spain), Open University UK (England) and University of South Australia (Australia) appears to be included.

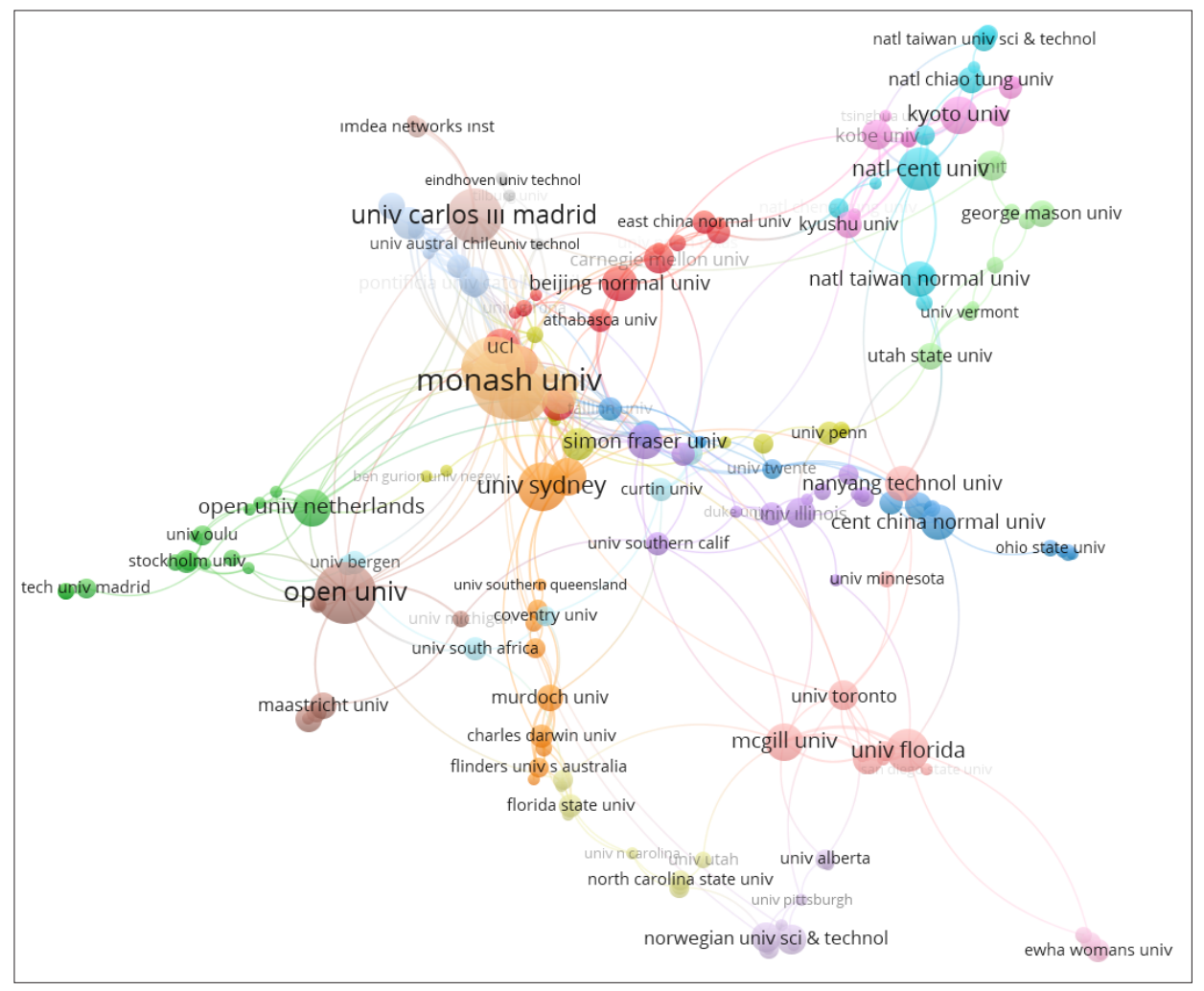

Fig. 4. The institution collaboration network. 


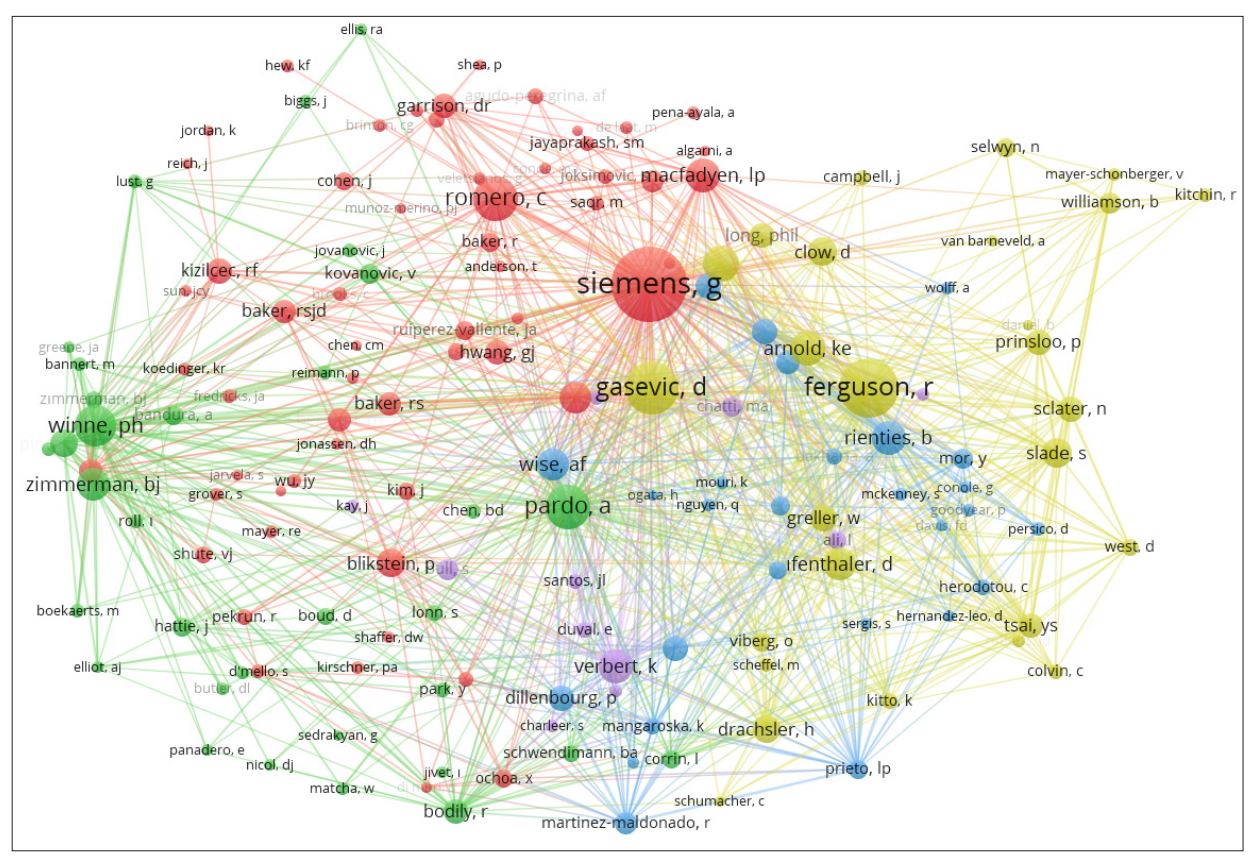

Fig. 5. Co-citation (author) Network.

\subsection{Co-Citation Analysis}

The network structure of the co-citation analysis of the publications on learning analytics studies is shown in Fig. 5.

In Fig. 5, different colors represent different clusters. Also, each round shape represents an author. The big size of circle indicates the dominance of cited publications. If there is a dash between the names of two authors, it is stated that these two authors are working together. When the common citation network is examined, six clusters are seen which were differently colored. Authors with multiple citations are accumulated in the same cluster. The publications located in the center generally show that they were cited from different disciplines and have more complicated links with other clusters. Examining the whole of Fig. 5, the red, green, yellow and blue clusters are larger and more evident than the others. Also, "Siemens, G.", "Gasevic, D.", "Ferguson, R.", "Pardo, A.", "Romero, C.", "Winne, P. H." and "Martinez-Maldonado, R." seems to be relatively located in the central of the network and appears to be associated with many different clusters

\subsection{Co-Occurrences Analysis}

Keyword analysis is a crucial and necessary process to define the knowledge structure of the learning analytics field and to clarify current issues on the subject. In this context, 
a network structure was created, in which the relations between the keywords were created. The results regarding this are shown in Fig. 6.

There are 1614 keywords related to the subject. The size of the circle shows the most discussed topic, and the yellow areas show the updated topics. It is seen that many keywords such as educational data mining, learning analytics, online learning, flipped learning, MOOCS, blended learning, social network analysis are frequently used according to the size of the circle and the number of links. Therefore, in general, learning analytics studies are carried out with educational data mining, MOOCs, dashboards, and machine learning. These keywords are concepts that have been studied together with other clusters. They have been determined as the most frequently encountered keywords. It is noteworthy that current topics include precision education, creativity, game-based learning, log analysis, course design, artificial intelligence, deep learning. The up to dated topics may help researchers to understand the trends of the topic.

When the most cited publications are examined, data mining, MOOC, social learning, self-directed learning, online learning, adaptive learning, and predicting academic success are the most trending areas of study in the field of learning analytics. This situation is also consistent with the results of the common keyword analysis. It is also evident from the common keyword analysis that researchers are working on learning analytics and data mining along with current learning methods such as flipped learning, blended learning and game-based learning. This shows that the interest in learning analytics research that predicts academic success will continue in the future.

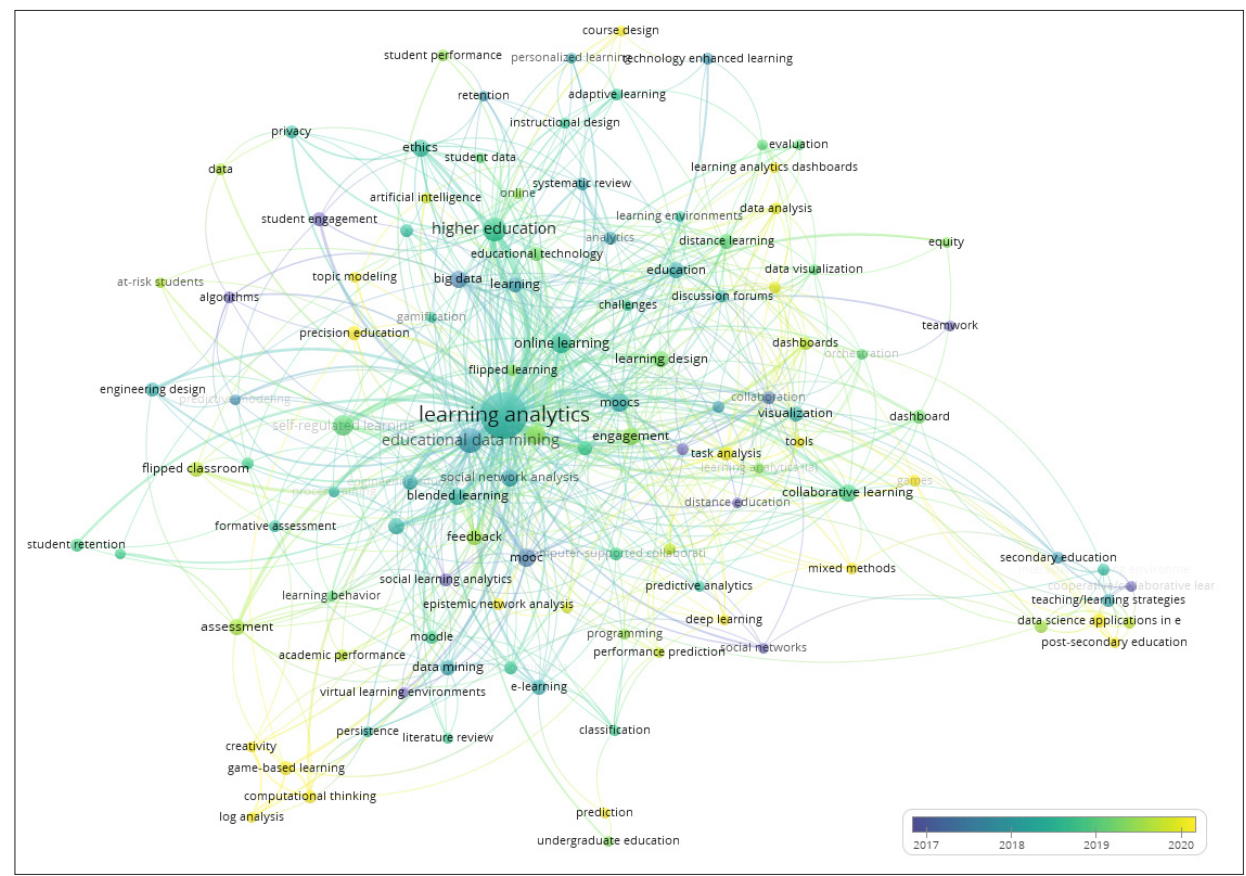

Fig. 6. A co-occurrence network of keyword. 


\section{Discussion}

The current study is a comprehensive overview of scientific studies conducted about learning analytics in the WoS database from since 2011. Findings were revealed through descriptive and bibliometric analyses. VOSviewer visual mapping software was used to analyze the current situation and development trends on the subject from many aspects and to visualize all this information. In the study, primarily the distribution of publications by years and citation numbers was examined. Then, the most published journals on the subject, the most frequently cited publications, the most prolific countries, institutions and authors are given. In addition, the cooperation between countries, authors and institutions that publish on the subject is also mentioned. Finally, the network structure was created for the relationships between the keywords.

According to the results obtained, it was observed that basic research on the subject started in 2011. 2011 is the year SoLAR was established and learning analytics field became an active research area. Although it is stated in the literature that research in this field first emerged in 1995 (Zhang et al., 2018), key terms such as data mining, EDM, higher education and e-learning stand out in this field before 2011 (Waheed et al., 2018). It was also determined that there was an increase from the past to the present in the studies conducted in general, and the highest number of publications reached in 2020. It can also be stated that the number of citations has increased over the years. Therefore, although learning analytics is a relatively new field of research, it can be stated that the interest in the subject has increased over time. In conclusion, it can be said that research in this field has progressed in recent years, and countries around the world have joined this research community and contributed to the field. Similar to our study results, it has been observed in the literature that the concept of learning analytics has started to be expressed more clearly by different researchers since 2011 and the number of publications generally increases every year (Adeniji, 2019; Du et al., 2019; Waheed et al., 2018; Zhang et al., 2018). It can be said that the dramatic rise may be related to the increase in the volume of student data in learning management systems. In addition, it can be stated that technological developments in data storage and data retrieval increase the usability and accessibility of learning analytics data (Adeniji, 2019).

When the countries/regions where learning analytics applications are carried out in terms of productivity are examined, it will be seen that the USA is prominent in learning analytics in terms of publication output and number of citations, followed by Australia, Spain and England. It can be said that the USA and Europe, with their international project partnerships and universities that support this work, have invested heavily in this business and have a prevalence in the literature of this important field, both in terms of quality and quantity. It has been determined that similar results have been reached in the literature and that the USA, Spain, England and Australia are the leading countries in the learning analytics literature (Adeniji, 2019; Waheed et al., 2018). One of the countries that has invested heavily in this field in recent years and has come to the fore in the number of publications is China. When institutions are considered in terms of productivity, the University of Edinburgh (Scotland) and Open University UK (England) stand out as 
the most prolific institutions in terms of the total number of citations. Some of the most influential authors in this field also serve in these institutions. Monash University is the most prolific institution in terms of number of publications. In addition, four of the institutions are located in Australia.

According to the results of the research, the most frequently cited publication belongs to Greller \& Drachsler (2012). The author is followed by the publications of Shum \& Ferguson (2012), Kizilcec et al. (2017) and Papamitsiou \& Economides (2014), respectively. On the other hand, Zhang et al. (2018) found that the most frequently cited publications are Romero \& Ventura (2010), Baker \& Yacef (2009) and Macfadyen \& Dawson (2010). Again, Waheed et al. (2018), it was determined that the most cited publications on the subject belong to Romero and Ventura (2010). However, when the publications of these authors are examined, it is seen that the publications deal with Educational Data Mining. In the same study, it was stated that Ferguson (2012) was cited most frequently in his publication (Waheed et al., 2018). Ferguson (2012) discussed the importance of learning analytics, its difference from academic analytics, the difficulties of providing datasets, and the ethical issues associated with it, thus providing an overview of this field and laying the foundation for the learning analytics literature.

When the publication and citation numbers of the most prolific and influential authors were examined, it was determined that Gasevic, Pardo and Dawson came to the fore. The fact that these authors are among the leading authors on learning analytics suggests that this result is not surprising. Four of the 10 most prolific authors in publishing articles on this research theme are in Australia, demonstrating this country's superiority in the field. Additionally, most of these authors are from Monash University, University of South Australia, Universidad Carlos III de Madrid, covering the connections of the most important teams in this field. Similarly, Waheed et al. (2018) concluded that Pardon and Dawson are the authors who contributed the most to this research field in terms of the number of publications. On the other hand, Zhang et al. (2018) found that Romero C., Siemens G., Breiman L., and Ferguson R. are the most prolific and influential authors in this research area.

When the distribution of the journals that published the most on the subject was examined, it was determined that the important journals related to the use of technology in education came to the fore. The most widely published journals are Interactive Learning Environments, British Journal of Educational Technology and Computers \& Education. When the number of citations per article is analyzed, Educational Technology Society, Computers \& Education and British Journal of Educational Technology stand out in this field. On the other hand, Waheed et al. (2018) determined that the most published journals on the subject were Computers \& Education and Computers in Human Behavior. Similar to our study results, in the research conducted by Adeniji (2019), Interactive Learning Environments, Computers and Education, British Journal of Educational Technology and Educational Technology and Society are among the most published journals. These journals, which are among the journals with the highest H-index, are of great interest among academics and researchers with the highest number of citations and the highest average number of citations per published article. 
When the co-author analysis of the publications on the subject was examined, it was concluded that the authors who published together generally had publications separately and in small groups. In addition, it has been determined that there are also authors who make individual publications. Examples of outstanding writer collaborations are Gasevic, Pardo, Dawson and Jovanovic. These authors can be expressed as the most cited authors in the field and cited in studies conducted in many different fields. On the other hand, when the countries/regions of the co-authors are examined, it has been determined that the USA, Spain, England, Netherlands, Australia, Germany and France work together with many countries. In addition, it is seen that many institutions in these countries (Monash University, University of Sydney, Universidad Carlos III De Madrid, University of South Australia etc.) use learning analytics effectively and produce many publications in this field. The widespread use of online learning environments in higher education causes learning analytics to be more popular in these institutions. Thanks to the learning analytics tools used, precautions can be taken for learners who are at risk of failure. Common word analysis reflects the content analysis of the studies examined and ensures that common repetitive concepts are revealed (Gulmez et al., 2021; Talan, 2021). Learning analytics, educational data mining, flipped learning, online learning, MOOCS, blended learning, social network analysis, are the most prominent concepts.

Learning analytics, which has been intensively studied recently, has many purposes and benefits such as improving teaching, increasing the quality of teaching, predetermining the risk situations and problems of learners, and making predictions for the future to increase the success of learners. In addition, the effective use of forecasting and action structures in order to better understand and meet the needs of each of the learners, trainers and educational institutions and to make the necessary adjustments is possible thanks to learning analytics. Therefore, educational institutions around the world are making more use of learning analytics technologies every day to have more effective and efficient learning processes. Although the number of scientific researches on learning analytics is increasing day by day, approaching the researches in this field with a general point of view provides the opportunity to see the effectiveness and progress of scientific publications on this subject. In this respect, in order to contribute to the development of the relevant literature in our research, scientific publications made with learning analytics in the WoS database were tried to be revealed in terms of bibliometric indicators. It is thought that the results obtained in the research will guide the field experts to determine different study topics, will benefit researchers and practitioners, and can be a source they can apply for new research on this subject.

\section{References}

Adeniji, B.A. (2019). A Bibliometric Study on Learning Analytics. Master's Thesis, Long Island University, New York, NY, USA.

Agaoglu, M. (2016). Predicting instructor performance using data mining techniques in higher education. In: IEEE Access, 4, 2379-2387. DOI: 10.1109/ACCESS.2016.2568756.

Al, U., Soydal, İ. (2012). The impact of journal self-citation: The case of energy education science and technology. The Journal of Turkish Librarianship, 26(4), 699-714. 
Badra, G., Algobail, A., Almutairia, H., Almuterya, M. (2016). Predicting students' performance in university courses: A case study and tool in KSU mathematics department. Procedia Computer Science, 82, 80-89. https://doi.org/10.1016/j.procs.2016.04.012

Booth, M. (2012, July/August). Learning analytics: The new black. EDUCAUSE Review, 47(4), 52-53. Retrieved June, 2021, from http://www.educause.edu/ero/article/learning-analytics-new-black

Bozkurt, A. (2016). Öğrenme analitiği: e-öğrenme, büyük veri ve bireyselleştirilmiş öğrenme. $A U A d, 2(4)$, 55-81.

Casey, K., Azcona, D. (2017). Utilizing student activity patterns to predict performance. International Journal of Educational Technology in Higher Education, 14, 1-15. https://doi.org/10.1186/s41239-017-0044-3

Daniel, B.K. (2017). Big data in higher education: The big picture. In: Big Data and Learning Analytics in Higher Education, 19-28. Cham, Switzerland: Springer.

Dawson, S., Gasevic, D., Siemens, G., Joksimovic, S. (2014). Current state and future trends: A citation network analysis of the learning analytics field. Paper presented at: The Sixth International Conference on Learning Analytics \& Knowledge, Indianapolis, Indiana. New York: ACM. https://doi.org/10.1145/2567574.2567585

Del Blanco, A., Serrano, A., Freire, M., Martinez-Ortiz, I., Fernandez, M., B. (2013, March). E-learning standards and learning analytics. Can data collection be improved by using standard data models? Paper presented at the Global Engineering Education Conference (EDUCON). Berlin, Germany: IEEE.

Du, X., Yang, J., Shelton, B.E., Hung, J.L., Zhang, M. (2019). A systematic meta-review and analysis of learning analytics research. Behaviour and Information Technology, 1-14.

https://doi.org/10.1080/0144929X.2019.1669712

Dyckhoff, A.L., Zielke, D., Bültmann, M., Chatti, M.A., Schroeder, U. (2012). Design and implementation of a learning analytics toolkit for teachers. Educational Technology \& Society, 15(3), 58-76.

Elias, T. (2011). Learning analytics: Definitions, processes and potential. Retrieved May, 2021, from http://learninganalytics.net/LearningAnalyticsDefinitionsProcessesPotential.pdf

Ferguson, R. (2012). Learning analytics: Drivers, developments and challenges. International Journal of Technology Enhanced Learning, 4(6), 304-317. https : //doi .org/10.1504/I JTEL . 2012.051816

Fidalgo-Blanco, Á., Sein-Echaluce, M.L., García-Peñalvo, F.J., \& Conde, M.Á. (2015). Using learning analytics to improve teamwork assessment. Computers in Human Behavior, 47, 149-156. https://doi.org/10.1016/j.chb.2014.11.050

Fritz, J. (2011). Introduction to learning and knowledge analytics: An open online course (Guest speaker).

Ga ević, D., Dawson, S., Rogers, T., Gasevic, D. (2016). Learning analytics should not promote one size fits all: The effects of instructional conditions in predicting academic success. The Internet and Higher Education, 28, 68-84. https://doi.org/10.1016/j.iheduc.2015.10.002

Gaviria-Marin, M., Merigó, J.M., Baier-Fuentes, H. (2019). Knowledge management: A global examination based on bibliometric analysis. Technological Forecasting and Social Change, 140, 194-220. https://doi.org/10.1016/j.techfore.2018.07.006

Greller, W., Drachslrer, H. (2012). Translating learning into numbers: A generic framework for learning analytics. Educational Technology \& Society, 15(3), 42-57.

Gulmez, D., Ozteke, I., Gumus, S. (2021). Overview of educational research from Turkey published in international journals: A bibliometric analysis. Education and Science, 46(206), 213-239. https://doi.org/10.15390/EB.2020.9317

Ibrahim, Z., Rusli, D. (2007). Predicting students' academic performance: Comparing artificial neural network, decision tree and linear regression. 21st Annual SAS Malaysia Forum, Kuala Lumpur, 1-6.

Ifenthaler, D., Widanapathirana, C. (2014). Development and validation of a learning analytics framework: Two case studies using support vector machines. Technology, Knowledge and Learning, 19(2), 221-240. https://doi.org/10.1007/s10758-014-9226-4

Johnson, L., Adams, S., Cummins, M. (2012). The NMC Horizon Report: 2012 Higher Education Edition. Austin, Texas: The New Media Consortium.

Johnson, L., Adams, S., Cummins, M., Estrada, V., Freeman, A., Ludgate, H. (2013). NMC Horizon Report: 2013 Higher Education Edition. Austin, Texas: The New Media Consortium.

Johnson, L., Smith, R., Willis, H., Levine, A., Haywood, K., (2011). The 2011 Horizon Report. Austin, Texas: The New Media Consortium.

Khalil, M., Ebner, M. (2015). Learning analytics: Principles and constraints. In: Proceedings of World Conference on Educational Multimedia, Hypermedia and Telecommunications, EdMedia 2015, AACE, Waynesville, NC, USA (2015), pp. 1326-1336. 
Kloos, C.D., Pardo, A., Muñoz-Merino, P.J., Gutiérrez, I., Leony, D. (2013). Learning analytics @ UC3M. In: 2013 IEEE Global Engineering Education Conference (EDUCON). pp. 1232-1238, Berlin, Germany. https://doi.org/10.1109/EduCon.2013.6530264

Koca, M.H. (2019). Prediction of Secondary School Students' Course Achievement Levels Using Learning Analytics. Master Thesis, Yıldız Teknik University, Istanbul.

Lu, O.H., Huang, J.C., Huang, A.Y., Yang, S.J. (2017). Applying learning analytics for improving students engagement and learning outcomes in an MOOCs enabled collaborative programming course. Interactive Learning Environments, 25(2), 220-234. https : //doi .org/10.1080/10494820.2016.1278391

Macfadyen, L., Dawson, S. (2010). Mining LMS data to develop an "early warning system" for educators: A proof of concept. Computers \& Education, 54(2), 588-599. https://doi.org/10.1016/j.compedu.2009.09.008

Marks, A., Al-Ali, M., Rietsema, K. (2016). Learning management systems: A shift toward learning and academic analytics. International Journal of Emerging Technologies in Learning, 11(4), 77-82. https://doi.org/10.3991/ijet.v11i04.5419

Osmanbegović, E., Suljić, M. (2012). Data mining approach for predicting student performance. Economic Review: Journal of Economics and Business, 10(1), 3-12.

Papamitsiou, Z., Economides, A. (2014). Learning analytics and educational data mining in practice: A systematic literature review of empirical evidence. Educational Technology \& Society, 17(4), 49-64.

Pritchard, A. (1969). Statistical bibliography or bibliometrics. Journal of Documentation, 25, 348-349.

Rienties, B., Cross, S., Zdrahal, Z. (2017). Implementing a learning analytics intervention and evaluation framework: What works? In: B. Kei-Daniel (Ed.), Big Data and Learning Analytics in Higher Education (pp. 147-166), Cham: Springer. https ://doi.org/10.1007/978-3-319-06520-5_10

Romero, C., Sebastian V. (2010). Educational data mining: A review of the state of the art. IEEE Transactions on Systems, Man, and Cybernetics, Part C (Applications and Reviews) 40: 601-618.

Siemens, G. (2010). What are learning analytics? Elearnspace. Retrieved from http://www . elearnspace.org/blog/2010/08/25/what-are-learning-analytics

Siemens, G. (2013). Learning analytics: The emergence of a discipline. American Behavioral Scientist, 57(10), 1380-1400. https://doi.org/10.1177/0002764213498851

Siemens, G., Gasevic, D. (2012). Guest editorial - learning and knowledge analytics. Educational Technology \& Society, 15(3), 1-2.

Siemens, G., Long, P. (2011). Penetrating the fog: Analytics in learning and education. EDUCAUSE Review, 46(5), 30-32.

Siemens, G., Dawson, S., Lynch, G. (2013). Improving the quality and productivity of the higher education sector. Policy and Strategy for Systems-Level Deployment of Learning Analytics. Canberra, Australia: Society for Learning Analytics Research for the Australian Office for Learning and Teaching. Retrieved June 12, from http://solaresearch.org/Policy_Strategy_Analytics.pdf

Sin, K., Muthu, L. (2015). Application of big data in educational data mining and learning analytics - a literature review. ICTAC Journal of Soft Computing, 5(4), 1035-1049.

Slade, S., Prinsloo, P. (2013). Learning analytics: Ethical issues and dilemmas. American Behavioral Scientist, 57(10), 1510-1529. https://doi.org/10.1177/0002764213479366

Talan, T. (2021). Artificial intelligence in education: A bibliometric study. International Journal of Research in Education and Science (IJRES), 7(3), 822-837. https://doi .org/10.46328/ijres . 2409

Tempelaar, D.T., Rienties, B., Giesbers, B. (2015). In search for the most informative data for feedback generation: Learning Analytics in a data-rich context. Computers in Human Behavior, 47, 157-167. https://doi.org/10.1016/j.chb.2014.05.038

Verma, S., Thakur, R. (2017). Fuzzy association rule mining based model to predict students' performance. International Journal of Electrical and Computer Engineering (IJECE), 7(4), 2223-2231. https://doi.org/10.11591/ijece.v7i4.pp2223-2231

Viberg, O., Hatakka, M., Bälter, O., Mavroudi, A. (2018). The current landscape of learning analytics in higher education. Computers in Human Behavior, 89, 98-110. https://doi.org/10.1016/j.chb.2018.07.027

Waheed, H., Hassan, S.U., Aljohani, N.R., Wasif, M. (2018). A bibliometric perspective of learning analytics research landscape. Behaviour \& Information Technology, 37(10-11), 941-957. https://doi.org/10.1080/0144929X.2018.1467967

Wang, T., Mitrovic, A. (2002). Using neural networks to predict student's performance. In: Proceedings International Conference on Computers in Education. pp. 969-973 vol.2, https://doi.org/10.1109/CIE. 2002.1186127 
West, D.M. (2012). Big data for education: Data mining, data analytics, and web dashboards. Governance Studies at Brookings, pp. 1-10. Retrieved June 27, 2021, from

http: //www . brookings.edu/ /media/Research/Files/Papers/2012/9/04\%20education $\% 20$ technology $\% 20$ west $/ 04 \% 20$ education $\% 20$ technology $\% 20$ west.pdf

Wise, A.F. (2014, March). Designing pedagogical interventions to support student use of learning analytics. Paper presented at the 2nd International Conference on Learning Analytics and Knowledge, pp. 203-211. Vancouver, Canada. https://doi.org/10.1145/2567574.2567588

Zhang, J., Zhang, X., Jiang, S., Ordóñez de Pablos, P., Sun, Y. (2018). Mapping the study of learning analytics in higher education. Behaviour \& Information Technology, 37(10-11), 1142-1155. https://doi.org/10.1080/0144929X.2018.1529198

Zilvinskis, J., Willis, J.E. (2019). Learning analytics in higher education: A reflection. InSight: A Journal of Scholarly Teaching, 14, 43-54.

T. Talan is an Assistant Professor in the department of computer engineering at Gaziantep Islam Science and Technology University. He has received the BSc degree in Department of Computer Education and Instructional Technology from Inonu University in 2005; MSc degree in Educational Technology from Suleyman Demirel University in 2014 and PhD degree from Istanbul University Informatics Department in 2018. His research areas include meta-analysis, meta-thematic analysis, bibliometric analysis, blended learning, distance learning, augmented reality, and use of social media in education. He has published his academic works in national and international journals.

M. Demirbilek holds Doctoral degrees in Curriculum \& Instruction and master's in Curriculum \& Instruction specializing in Educational Technology from School of Education at the University of Florida. He also holds B.S. and M.S. degrees in electronics engineering from Istanbul University. Currently he works Educational Sciences Department in the Faculty of Education at Suleyman Demirel University. He worked as a Post-Doctoral Researcher at Games, Learning, and Society (GLS) research group at the University of Wisconsin-Madison (2008-2009) on mobile media project supported by The MacArthur Foundation. As a graduate faculty and visiting research scholar in Digital Worlds Institute at University of Florida (UF) between 2013 and 2014, he taught "Video Games \& Startups" course and advised graduate students. Dr. Demirbilek joined several European Union founded projects as the partner and IT expert. 
